JORNALISMO.

\title{
Técnicas de reportagem e realismo mágico em Relato de um náufrago, de Gabriel García Márquez
}

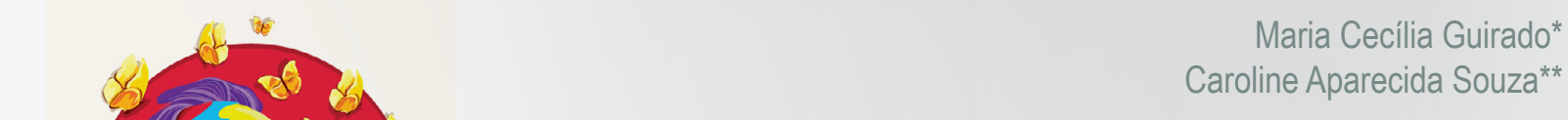

Caroline Aparecida Souza**

*Maria Cecilia (Ciça) Guirado, es brasilera, periodista, Master en Comunicación y Semiótica, en la Pontificia Universidade Católica de São Paulo y Doctora en Historia de la Comunicación, de la Universidade Nova de Lisboa. Enseña en la Universidade Estadual de Londrina. Publicó Relatos do descobrimento do Brasil: as primeiras reportagens, Editora Piaget, Lisboa en 2002 y Reportagem: a arte da investigação, Arte \& Ciência, São Paulo, en 2004. Desarrolló la investigación de campo de sus estudios postdoctorales en el Caribe colombiano con el provecto: Del periodismo a la literatura en Cien años de soledad, Apoyado por la Universidad de Cartagena.

Orcid. https://orcid.org/0000-0003-4629-6903?lang=en

Email: ceciliaguirado@hotmail.com

${ }^{*}$ Caroline Aparecida de Souza, es diplomada em Comunicación Social - Periodismo, em 2016, con el Trabajo de finalización del curso Realismo Mágico "Técnicas de Reportaje y Realismo mágico, en Relato de un Náufrago, de Gabriel Garcia Márquez". Investigadora del proyecto Imágenes de la América Latina: texto periodístico-literário de Gabriel García Márquez (2012 - 2016), coordinado por la profesora María Cecilia Guirado en la Universidad Estadual de Londrina (UEL) - Londrina - PR - Brasil. Actualmente trabaja como redactora de periodismo digital en el portal Londrinatur. Email: carolineap.desouza29@gmail.com 


\section{JOURNALISM.}

\section{Reporting techniques and magical realism in the story of a Shipwrecked Sailor, of Gabriel García Márquez}

\section{SUMMARY}

The latin-american writer Gabriel García Márquez was responsible for a vast journalistic work to press. His reporting techniques, without the use of a recorder, with the attention directed to the expressions of the interviewed and the conjectures of investigation, resulted in exquisite journalistic texts, plated by the magic realism. This article observes Gabriel García Márquez's journalistic techniques on the production of the work The Story of a Shipwrecked Sailor, which was firstly published as a serial in the newspaper El Espectador. It is observed, in this study, the apprehension of the facts and the creative process of the journalist Gabriel Garcia Márquez by the lens of the semiotics of Charles Sanders Peirce.

Keywords: Gabriel Garcia Márquez; Magic Realism, Reporting techniques, semiotics.

Received. June 07, 2017

Accepted. July 03, 2017

\section{PERIODISMO.}

\section{Técnicas de reportaje y realismo mágico en el Relato de un náufrago, de Gabriel García Márquez}

\section{RESUMEN}

El escritor latinoamericano Gabriel García Márquez fue responsable de una amplia obra periodística. Sus técnicas de reportaje, sin el uso de grabadora, con la atención dirigida hacia las expresiones del entrevistado y a las conjeturas de investigación, dieron como resultado exquisitos textos periodísticos, bañados por el realismo mágico. Este artículo observa las técnicas periodísticas utilizadas por este escritor, en Relato de un náufrago, publicado inicialmente en formato de folletín, en el periódico El Espectador. Se observa, en este estudio, la aprehensión de los hechos y el proceso creativo de este periodista a la luz de la semiótica de Charles Sanders Peirce.

Palabras Clave: Gabriel García Márquez; realismo mágico; técnicas de reportaje; semiótica.

Recibido. Junio 07, 17 Aceptado. Julio 03, 2017 


\section{Introdução}

Nada é mais fascinante ou mágico que a própria realidade. Gabriel García Márquez

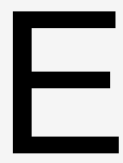
ra 28 de fevereiro de 1955. A Colômbia se agitava com a notícia de que oito tripulantes do destróier Caldas haviam caído ao mar e desaparecido. Até então se sabia que o navio da Marinha de Guerra da Colômbia voltava de Mobile, nos Estados Unidos, para o porto de Cartagena e uma tormenta no Mar do Caribe teria ocasionado a tragédia. As buscas começaram de imediato, com a ajuda das forças norte-americanas do Canal do Panamá, mas depois de quatro dias se encerraram, sem esperança de encontrar sobreviventes. Uma semana depois, um dos marinheiros desaparecidos foi encontrado em uma praia deserta ao norte da Colômbia. Seu nome era Luís Alejandro Velasco (García Márquez, 1999, p. 3).

Ele foi internado no Hospital Naval de Cartagena e um guarda foi colocado em sua porta para que ninguém perguntasse sobre o que havia acontecido. Jornalistas de todo o país chegavam à cidade para produzir reportagens sobre o naufrágio e tentar fotografar Velasco. Nessa época, Gabriel García Márquez era repórter do El Espectador de Bogotá e também tentava uma entrevista com o marinheiro, que era supervisionado todo o tempo. As perguntas do jornalista eram sempre respondidas pelo tenente de fragata Guillermo Fonseca. O ano era o segundo do regime ditatorial do general Gustavo Rojas Pinilla. A imprensa estava censurada, não podia publicar qualquer assunto com implicações políticas.

García Márquez começou a pensar que algo de muito importante poderia ter acontecido e que o estavam impedindo de levar à público. Era um presságio, como mais tarde relatou em seu livro Viver Para Contar.
Então ficou evidente que estávamos nas mãos de mestres na arte oficial de esfriar a notícia, e pela primeira vez fui abalado pela ideia de que estava escondendo da opinião pública alguma coisa muito grave sobre a catástrofe. Mais que uma suspeita, hoje em dia recordo daquela sensação como a de um presságio (2003, p.469).

Enquanto isso, o náufrago era condecorado pelo Presidente da República e proclamado herói da pátria. Concedia entrevistas aos meios de comunicação favoráveis ao regime, lucrando com campanhas publicitárias.

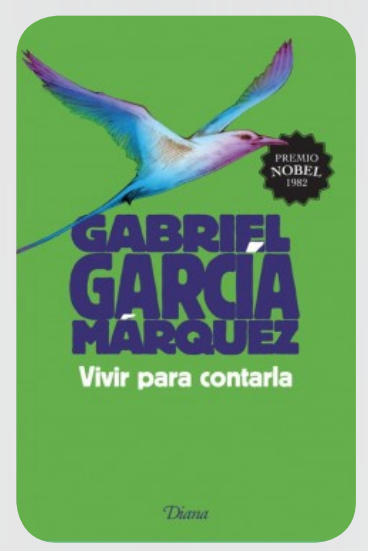

\section{Do naufrágio à glória: um primeiro olhar}

O marinheiro, depois de algum tempo, foi ao escritório do El Espectador para vender a sua história. García Márquez acreditava que o seu relato estava deturpado e que os leitores não se interessariam por esse tipo de herói. Além disso, ele já havia dado muitas entrevistas e "previa-se que já não tinha muito o que contar, que seria capaz de inventar qualquer coisa por dinheiro, e que o governo fixara muito bem os limites de sua declaração" (García Márquez, 1999, p. 5).

Guillermo Cano, diretor do jornal, propôs a García Márquez escrever a matéria, mas o jornalista se negou a fazer o que era sua obrigação. $O$ diretor chegou a despachar o náufrago, mas 
voltou atrás assim que o marinheiro saiu da redação. Pediu ao porteiro que o trouxesse de volta e comprou os direitos exclusivos do relato completo. García Márquez lembrou em Cheiro de Goiaba (1993), não era a primeira vez que Guillermo cismava com algum caso que todos julgavam perdido e acabava com razão. Como diria Ricardo Kotscho (1986) um repórter nunca deve desprezar uma pauta sem antes saber o que ela pudesse render, mesmo se o assunto não for agradável. García Márquez, porém, acabou aceitando fazer a reportagem por uma questão de obediência profissional, mas alertou que não a assinaria. E assim, em relação ao marinheiro Velasco, o Relato seria escrito "com sua própria maneira de falar e com suas próprias ideias, e assinado com o seu nome" (García Márquez, 2003, p. 462).

$\mathrm{Na}$ redação do bogotano El Espectador todos concordaram que se algum jornalista conseguisse uma entrevista com o náufrago, provavelmente seria a "reportagem do ano". García Márquez foi incumbido de reescrever a história de Velasco pelo editor Guillermo Cano, a fim de trazer à tona o que estava encoberto.

O repórter sempre está em busca de um grande acontecimento, de um "furo" de reportagem. Ele espera apreender novos fenômenos e elaborar novas hipóteses, por meio do raciocínio abdutivo. Esse método objetiva "elaborar previsão geral sem qualquer garantia positiva de que ela se concretizará, seja no caso especial, seja nos casos comuns" (Peirce, 1984, p.112).

Quando soube do naufrágio e da impossibilidade de entrevistar o náufrago a um primeiro momento, García Márquez percebeu que Alejandro Velasco estava escondendo alguma coisa. Certamente fez uso do raciocínio abdutivo, enquanto planejava a pauta jornalística, que funciona como um diagrama de itens para observação e pesquisa. Hipóteses a desvendar durante qualquer uma das fases do processo de criação. Os elementos de alguma hipótese sobre algum "problema a desvendar" estão na cabeça do repórter antes mesmo que ele se conscientize disso.

A inspiração abdutiva acontece
em nós num lampejo. É um ato de
'insight', embora extremamente
falível. É verdade que os elementos
da hipótese estavam antes em nossa
mente; mas a ideia de associar
o que nunca antes pensáramos
em associar que faz lampejar a
inspiração abdutiva em nós (Peirce,
1974, p.57).

García Márquez baseou-se em um conhecimento anterior sobre o náufrago, concluindo que ele teria algo a esconder. Não há como, segundo a visão peirceana, elaborar uma nova hipótese sem basear-se em um conhecimento anterior, com nível zero de informação sobre o assunto tratado.

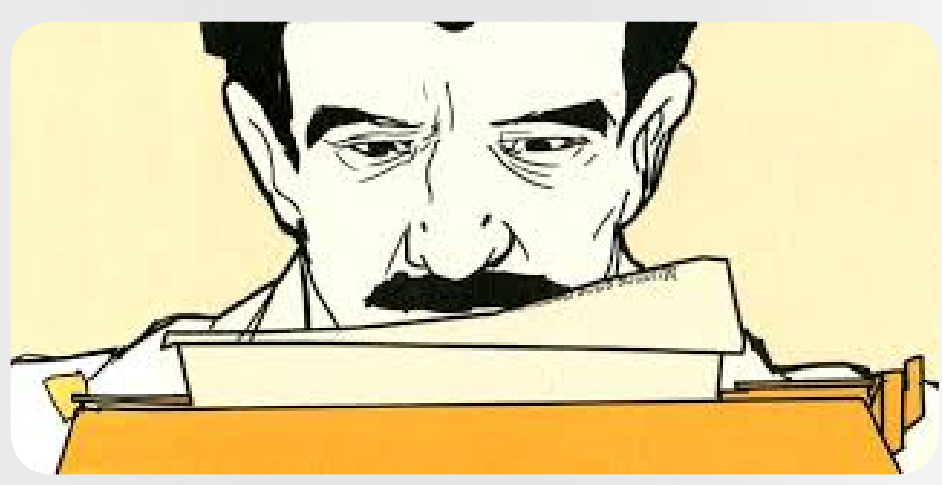

\section{O jornalista em seu labirinto: as técnicas de}

\section{reportagem}

A entrevista é uma técnica utilizada há muitos anos nas mais diversas áreas, como o setor de recursos humanos nas empresas e na prática clínica, por exemplo. Daisi Vogel conta que como designação de uma prática jornalística, a palavra entrevista começou a ser usada no final do século XIX:

Em jornalismo, a entrevista é ferramenta centralde trabalho e possui como função dominante a apuração de informações ou o conhecimento de um personagem com papéis muito claramente definidos para o entrevistado e o entrevistador. Nesse 
caso, são essenciais pelo menos dois interlocutores dispostos a falar sobre algum ou vários assuntos: uma das pessoas envolvidas cumpre o papel de entrevistador, donde supor que conduzirá os temas, e a outra desempenha o papel de entrevistado, o que Ihe atribui já de início alguma autoridade - a autoridade e o papel de quem tem algo a dizer (2009, $p$. 47).

Cumprindo o seu papel de "quem tem algo a dizer", o náufrago concedeu entrevistas reveladoras. Gabo, como era chamado pelos amigos, logo se surpreendeu com a inteligência, sensibilidade e educação do náufrago, assim como o seu senso de humor. Mas o estilo literário da escritura, assim como toda a atmosfera para seduzir o leitor, são peripécias do colombiano. Em vinte sessões de seis horas diárias, García Márquez tomava notas e fazia perguntas que pudessem fazer o náufrago cair em contradição, o que não aconteceu.

Durante o quarto dia de entrevista, o repórter teve uma surpresa. Ele pediu ao marinheiro que descrevesse a tormenta que resultou no desastre. Com um sorriso, ele simplesmente respondeu que não houvera tormenta alguma. García Márquez investigou nos serviços meteorológicos sobre as condições climáticas no dia do acidente e soube que aquele havia sido um dos fevereiros mais mansos de toda a história do Caribe. Soube também que o navio tombou por causa do vento e do mar agitado, que soltou a carga que estava mal estivada na coberta e lançou os oito marinheiros ao mar.

García Márquez, com seu rigoroso e exaustivo questionamento, bem como a busca de novos ângulos, havia inadvertidamente revelado que o barco não tinha se inclinado e virado numa tempestade violenta, mas sim que afundara porque carregava mercadoria ilegal, que não estava adequadamente assegurada; e que a regulamentação dos procedimentos de segurança era grosseiramente inadequada (Martin, 2010, p. 227).
A essência do trabalho do repórter é sempre a mesma, diz Ricardo Kotscho (1986), não importa se está cobrindo um acidente de trânsito na esquina do jornal ou a morte de um Papa. A sua função é contar o que aconteceu, sem parar de investigar enquanto ele próprio não estiver satisfeito com o texto que construiu.

Já de posse das informações, o jornalista quis verificá-las para que se aproximassem do que era verdadeiro. Nesta etapa da produção, García Márquez fez uso do raciocínio indutivo, que não sugere novas ideias, mas para averigua as informações pré-reunidas. É o momento em que se testa os dados, os compara com semelhantes e até os confronta com outras fontes.
Ora, crer numa regra é fruto de hábito. Que o hábito seja uma regra ativa em nós, é evidente. Que toda crença tenha natureza de um hábito, na medida em que é de caráter geral, foi demonstrado em trabalhos que anteriormente publiquei. A indução é, portanto, a fórmula lógica, que expressa o processo fisiológico da formatação de um hábito (Peirce, 1984, p. 163).

Com base nas informações checadas, o colombiano tomou consciência de todos os erros que aquela revelação lhe indicava, implicando em danos morais e políticos que não havia imaginado antes, já que "primeiro, era proibido transportar carga em um destróier; segundo, foi por causa do excesso de peso que o navio não pôde manobrar para resgatar os náufragos; terceiro, tratava-se de contrabando: geladeiras, televisores, máquinas de lavar" (García Márquez, 1999, p. 6).

O último raciocínio que Peirce estuda é a dedução. Ele afirma que este é o momento em que os diversos juízos perceptivos se unem em um todo e transforma essa proposição copulativa de forma a colocar certas partes em ligação mais íntima, organizando-as. 
Na dedução, partimos de um estado de coisas hipotético definido abstratamente por certas características. Entre as características a que não se dá atenção neste tipo de argumento está a conformidade do estado das coisas com o mundo exterior. (...) $A$ inferência é válida se e somente se existe uma relação entre o estado de coisas suposto nas premissas e o da conclusão (PEIRCE, 1974, p. 50).

O resultado das entrevistas que passaram por esses métodos de raciocínio - abdução, indução e dedução - foi publicado em folhetim, durante 14 dias consecutivos. A tendência francesa do folhetim foi trazida aos países latinoamericanos e muitos dos grandes romances foram publicados, inicialmente, nesse formato. O El Espectador também usou o suspense do folhetim para publicar o Relato, prendendo os seus leitores até o próximo dia.

Para preparar os leitores do jornal, García Márquez e o editor Guillermo Cano decidiram começar o relato pelos últimos dias de Velasco em Mobile.

Também combinamos não terminar no momento de pisar em terra firme, mas quando chegasse a Cartagena aclamado pela multidão, que era o ponto a partir do qual os leitores podiam continuar por sua conta o fio da narração com as informações que já tinham sido publicadas (García Márquez, 1999, p. 463).

O governo acompanhava e estava satisfeito com o sucesso de seu herói, já que os jornais se esgotavam rapidamente nas bancas. Mas, quando a verdade sobre o acidente foi publicada as autoridades se puseram alerta. Devido ao número considerável de leitores que acompanhavam o folhetim, os governantes não se arriscaram a censurar a publicação, mas logo trataram de desmentir a revelação por meio de um comunicado oficial.

Depois da história ter sido completamente publicada, ela apareceu novamente em um suplemento especial, ilustrado pelas fotografias descobertas pelo repórter e que comprovavam a existência de contrabando. Muitos tentaram pressionar e ameaçar o náufrago, a fim de que ele mudasse o seu discurso. As autoridades também tentaram suborná-lo, mas ele não desmentiu o que havia declarado, o que resultou em sua expulsão da Marinha. Em pouco menos de dois anos a ditadura colombiana caiu e o país ficou entregue a outros regimes "melhor vestidos, mas não muito mais justos" (García Márquez, 1999, p.7). Nesta mesma época Márquez começou um exílio em Paris.

Ainda nas sessões diárias de entrevista, o jornalista surpreendia-se com aquele homem, de no máximo vinte anos, "mais com cara de trompetista que de herói da pátria" e que tinha uma habilidade narrativa assombrosa. O seu modo de contar era tão apaixonante e minucioso que o único problema literário do escritor era "conseguir que o leitor acreditasse nele" (García Márquez, 1999, p.5).

Nesse momento, o repórter usa os seus sentidos e a sua bagagem para captar o fenômeno, isto é, o distúrbio que gera a notícia. Em Viver para contar, Gabo disse que não foi usado gravador nesta entrevista, já que tinham acabado de ser inventados e os melhores eram grandes e pesados tal qual a uma máquina de escrever.

Tive de me conformar com o método habitual de tomar notas em cadernos escolares, mas graças a isso creio que não perdi nenhuma palavra e nenhuma nuance de conversa, e consegui ir mais fundo a cada passo. Os dois primeiros dias foram difíceis, porque o náufrago queria contar tudo ao mesmo tempo. No entanto, aprendeu logo graças à ordem e ao alcance das minhas perguntas, mas sobretudo graças ao seu instinto de narrador e à sua facilidade congênita para entender a carpintaria do ofício (2003, p. 463).

García Márquez sabia da utilidade do gravador em recordar os áudios, mas não queria se descuidar das expressões do entrevistado, que 
poderia dizer mais que a sua voz ou denunciálo em alguma mentira, afirmando a ideia de que “(...) Quando o personagem se abre, não é preciso a gente ficar falando dele. Ele mesmo faz seu próprio perfil, e o repórter trata apenas de prestar atenção para ser fiel ao que ouviu. Gravador, nestas horas, só atrapalha. O ideal é ficar papeando, anotar uma coisa ou outra" (Kotscho, 1986, p. 45).

Mesmo com o seu trabalho perspicaz de apreensão dos fenômenos, a mente do repórter não pode captá-los em sua total dimensão. Com base nas categorias fenomenológicas de Charles Sanders Peirce, pode-se comprovar a experiência:

Primeira - sentimento, a consciência que pode ser apreendida como um instante de tempo, consciência passiva da qualidade, sem reconhecimento ou análise; Segunda - consciência de uma interrupção no campo da consciência, sentido de resistência, de um fato externo ou outra coisa; Terceira - consciência sintética, reunindo tempo, sentido de aprendizado, pensamento (Peirce, 1977, p. 14)

$\mathrm{Na}$ primeiridade, Márquez se deparou com Alejandro Velasco no escritório do El Espectador e, sem analisar a fundo, concluiu que ele não teria muito o que dizer: era uma notícia velha e não traria qualquer novidade além do que já havia dito aos outros veículos de comunicação. Só aceitou após a insistência do editor Guillermo Cano.

Quando Márquez recebeu uma nova informação, gerou-se um conflito no campo da consciência, ou seja, a secundidade. Imaginou que o náufrago estaria escondendo alguma coisa, pois não podia dar entrevistas livremente aos jornais de oposição logo após o ocorrido. Submeteu o marinheiro a muitas perguntas para detectar alguma divergência em seu relato, o que não aconteceu. $\mathrm{E}$, finalmente, em nível de terceiridade, já em consciência sintética em relação ao fenômeno, à notícia, ele descobre a verdadeira causa do acidente e reconstrói o naufrágio de maneira encantadora, atraindo muitos leitores.

García Márquez não se contentou com as informações coletadas sobre 0 náufrago antes de conhecê-lo, obtidas por meio das entrevistas na televisão, no rádio e em outros veículos favoráveis ao governo da época. Esses signos pré-existentes em sua mente entraram em conflito, então, com os signos provindos da vivência que o náufrago compartilhou na entrevista.

\begin{abstract}
(...) sempre que pensamos, temos presente na consciência algum sentimento, imagem, concepção ou outra representação que serve como signo. Mas segue-se de nossa própria existência (o que está provado pela ocorrência da ignorância e do erro) que tudo o que está presente a nós é uma manifestação fenomenal de nós mesmos. Isto não impede que haja um fenômeno de algo sem nós, tal como um arco-íris é simultaneamente uma manifestação tanto do sol quanto da chuva. Portanto, quando pensamentos nós mesmos, tal como somos naquele momento, surgimos como um signo (Peirce, 1977, p. 269).
\end{abstract}

Há quem se pergunte se essa apreensão do fenômeno pelo jornalista pode se dar de maneira integral, sem perdas no caminho. Gabriel García Márquez, por exemplo, contou com o depoimento do náufrago e também as fotografias dos marinheiros para compor a sua narrativa. Poderia ele, então, chegar perto do que é considerada a "verdade" do fato?

O fenômeno, como foi dito anteriormente, não pode ser captado em toda a sua dimensão. $O$ signo que fará o papel de representar esse algo para alguém, não sendo o fenômeno ou coisa propriamente dita. Esse signo cria na mente da pessoa um signo equivalente ou até mais desenvolvido, entretanto, "Este Signo representa algo - seu Objeto - não em todos os aspectos [...]" (C.P.2.228). 
O jornalista será a pessoa que, ao trabalhar com os signos, tentará representá-los percorrendo um caminho ideal de interpretações. Gabriel García Márquez fez uso de algumas técnicas de reportagem conhecidas, como tomar notas em cadernos, não depender do gravador e se atentar mais às expressões do entrevistado, fazer perguntas que pudessem fazer o marinheiro cair em contradição e até pedir outros documentos que reforçassem o seu relato.

Com as anotações em mãos - diagrama inicial da investigação - o jornalista trabalha sobre os traços mais marcantes da observação, que dão acesso a uma reorganização mental do acontecimento. Ele pondera, pensa e analisa o que deve retratar, selecionando as facetas do assunto mais pertinentes com o propósito da investigação. Assim, García Márquez elaborou um roteiro para construir o texto: resolveu que o relato começaria pelos últimos dias de Velasco em terra firme, ainda em Mobile, e terminaria com o marinheiro sendo aclamado pela multidão em Cartagena, "que era o ponto a partir do qual os leitores podiam continuar por sua conta o fio da narração com as informações que já tinham sido publicadas (García Márquez, 2003, p. 463). Imagina-se, numa cadeira semiótica, que o propósito da pauta é transformar-se em investigação, que a intenção investigativa é pertencer ao propósito de elaboração do texto que, por sua vez, desembocará na publicação da reportagem.

Para realizar-se este objetivo, é necessário formar um plano de investigação e esta é a parte mais difícil de toda a operação. Não apenas temos de selecionar os traços do diagrama ao qual será pertinente prestar atenção, como também é da maior importância voltar mais de uma vez a certos traços. Caso contrário, embora nossas conclusões possam estar corretas, não serão as conclusões particulares que estamos visando (Peirce, 1974, p. 50).
Às tardes, Alejandro Velasco chegava à mesa de redação de García Márquez e juntos liam as anotações feitas no dia anterior e continuava a entrevista, seguindo a ordem linear. Ao anoitecer, Gabo escrevia o capítulo completo, que já era publicado no dia seguinte. Em 2003, o escritor contou em suas memórias que talvez fosse mais fácil e seguro escrever o relato completo e publicá-lo depois de revisado, com os detalhes comprovados. "Mas não dava tempo. O assunto ia perdendo a atualidade a cada minuto, e qualquer outra notícia barulhenta acabaria por derrotá-Io" (García Márquez, 2003, p. 463).

Compor o texto não é trabalho dos mais fáceis, entretanto. Assim como em um quebra cabeça, ele deve refletir e encaixar as frases de modo que complementem umas às outras, a fim de informar o leitor. Ricardo Kotscho (1986) garante que o objetivo dessas matérias é permitir que o leitor viaje com o texto e que o repórter se coloque no lugar das pessoas que não estavam lá e contar o que viu de maneira simples, como que escrevendo uma carta a um amigo.

\section{Delírios do real: realismo mágico no Relato}

A realidade mágica que permeava o naufrágio serviria como pano de fundo da narrativa. As práticas culturais da América Latina, segundo Andrews (1957), expressam influências de tradições europeias, adotadas em sua maioria pela classe média alta, e indígena, assimiladas pelas classes populares. Influências africanas também estão incrustradas nas características desse povo. Esse conjunto de misturas étnicas e culturais fez com que os escritores latinoamericanos rompessem com 0 realismo tradicional e fundissem a realidade à fantasia, resultando no realismo mágico. Ele, por sua vez, não é apenas uma distorção da realidade, mas uma ligação com a crença no sobrenatural. 
A vida cotidiana na América Latina nos demonstra que a realidade está cheia de coisas extraordinárias [...] Basta abrir os jornais para saber que entre nós acontecem coisas extraordinárias todos os dias. Conheço gente inculta que leu Cem Anos de Solidão com muito prazer e com muito cuidado, mas sem surpresa alguma, pois afinal não lhes conto nada que não pareça com a vida que eles vivem (GARCIA MÁRQUEZ, 1993, p. 39)

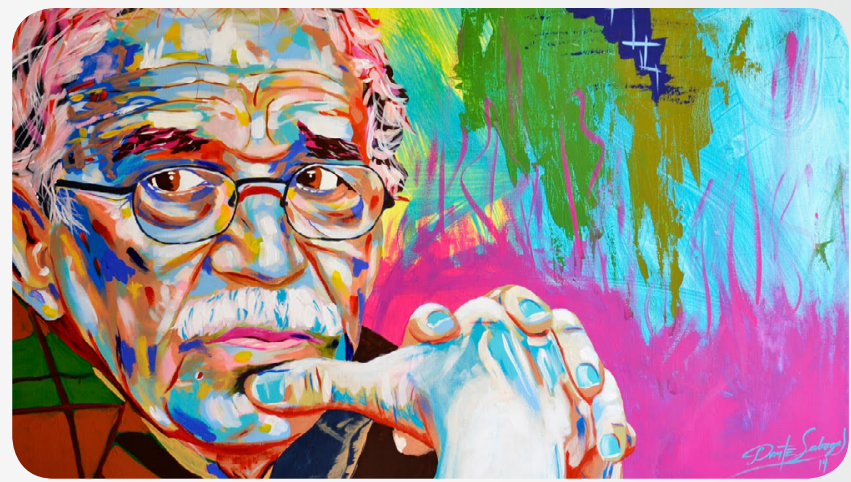

Segundo Herscovitz, esses escritores necessitavam escrever essa realidade mágica e completa: "Quem conhece a vida na América Latina sabe que o cotidiano surpreende mais do que a ficção" (2004, p. 177). O misticismo, um dos resultados do entrelaçamento cultural em território latino, é fator determinante na caracterização dessa literatura, criada por quem se depara com uma realidade mágica, ao contrário dos oriundos de outras localidades:

Um europeu, habituado só às pacíficas mudanças de estações - mudanças que se organizam no tempo e não no espaço não pode imaginar facilmente $o$ violento contraste entre o mundo do Mar das Antilhas e o mundo da Cordilheira dos Andes (...) Contraste humano, também. Descendente de andaluzes, de negros e de arrogantes índios caraíbas, 0 habitante da costa é aberto, alegre, alheio a todo dramatismo e sem nenhuma reverência por hierarquias e protocolos. Gosta de dança; ritmos africanos, percutidos, sobrevivem na sua música, que é sempre alegre (Garcia Marquez, 1993, p. 44.)
No Relato, alguns trechos não encontram explicações racionais e causam estranhamento. Em seu primeiro dia sozinho no Mar Caribe, Velasco passou a ouvir o amigo de naufrágio, há muito distante: "A brisa continuava uivando e, por cima do uivo da brisa, eu continuava ouvindo a voz de Luís Rengifo: "Gordo, reme para este lado"' (García Márquez, 1999, p. 40). Depois de muitos dias à deriva da balsa, com fome e sede, o náufrago passa a ver o amigo, que antes o atormentava apenas com sua voz.

Foi então que vi, sentado na coberta do destroier, o marinheiro Jaime Manjarrés, que me mostrava, com o indicador, a direção do porto. (...) No começo foi um sonho. Fechava os olhos, dormia durante breves minutos e aparecia sempre, pontual e na mesma posição, Jaime Manjarrés. Afinal decidi falar com ele. Não me lembro o que lhe perguntei nessa primeira vez. Não me lembro também o que me respondeu. Só sei que estávamos conversando na coberta e de repente houve o golpe da onda, a onda fatal das $11 \mathrm{~h} 55 \mathrm{~m}$; então, acordei sobressaltado, me agarrando com todas as forças ao estrado para não cair ao mar (Garcia Márquez, 1999 , p. 55).

Há quem defina o fantástico como "o que é criado pela imaginação, o que não existe na realidade, o imaginário, o fabuloso" (Rodrigues, 1988, p.9) e acaba por confundir o realismo mágico com a própria literatura, já que a segunda retrata a realidade imaginada. Entretanto, em suas conversas com Apuleyo Mendoza em Cheiro de Goiaba, Gabo revela que a imaginação é apenas um instrumento de elaboração da realidade, mas que a fonte de sua criação é sempre a realidade. A fantasia, isto é, a invenção pura e simples, sem nenhum pé na realidade, "é a coisa mais detestável que pode haver" (1999, p.34). Peirce, por sua vez, acredita que quando um homem busca pela verdade "seu primeiro esforço será imaginar o que aquela verdade pode ser. Ele não pode realizar seu propósito sem descobrir que a imaginação desenfreada o levará para fora dos trilhos" (C.P.1.46-8).

Com o passar dos dias, a linha entre a realidade 
e a ilusão se tornava ainda mais tênue para o marinheiro. Em certo momento da narrativa, Velasco quase desiste de nadar em direção à própria salvação ao avistar terra à frente da balsa. Tantos dias depois, achava que os coqueiros eram nítidos demais para serem verdadeiros e confundia-se com a sucessão dos dias.

No dia anterior, eu me vira numa festa em Mobile. Depois, vira uma gigantesca tartaruga amarela, e durante a noite tinha estado em minha casa de Bogotá, no Colégio La Salle de Villavicencio, e com os meus companheiros do destroier. Agora estava vendo a terra (García Márquez, 1999, p. 105).

García Márquez também retrata os estados de espírito do jovem marinheiro com maestria: resignação, desespero, esperança e até o medo que o acompanhou durante os seus dias no mar.

Minha primeira impressão, ao
perceber que estava submerso na
escuridão e já não podia ver a palma
da minha mão, foi a de que não
poderia dominar o terror. Pelo ruído
da água contra a borda, sabia que
a balsa continuava avançando lenta
mas incansavelmente. Afundado nas
trevas, vi então que não estivera só
durante o dia. Estava só na escuridão,
na balsa que não via mas que sentia
sob mim, deslizando silenciosamente
sobre um mar espesso e povoado de
animais estranhos (García Márquez,
1999, p. 42).

Foi com um relato humanizado da história do marinheiro, que se contrapunha ao heroísmo com que ele apareceu nas primeiras entrevistas, que García Márquez conquistou os leitores. Ler sobre a aventura de um náufrago "que esteve dez dias à deriva numa balsa, sem comer nem beber" e compartilhar dos seus medos e anseios certamente lhes despertou um sentimento de empatia.

\section{Considerações finais}

García Márquez é um dos romancistas com maior reconhecimento de todos os tempos, na América Latina, na Europa e nos EUA. Ele fundiu conceitos - realidade e ficção, jornalismo e literatura - de maneira muito sagaz e construiu uma narrativa rica em elementos de identificação para os latino-americanos.

O presente artigo retrata uma das primeiras experiências de Gabo em uma grande reportagem, ainda no jornal El Espectador. García Márquez, que estava mais habituado a tecer comentários sobre o cinema e cenas do cotidiano em pequenas colunas, se viu obrigado a reconstruir a história de um naufrágio que abalou o país. O emprego de suas técnicas de reportagem e a sensibilidade com que reescreveu o relato foram determinantes para o sucesso das publicações.

Além de observar as técnicas de reportagem utilizadas pelo escritor, a abordagem semiótica de Charles Sanders Peirce ajuda a compreender como o repórter organiza o seu trabalho, desde às primeiras hipóteses levantadas sobre o assunto, passando pela investigação, e terminando na construção da narrativa, de maneira clara e agradável ao leitor.

O jornalista latino-americano se deixou levar pela realidade mágica que o permeava para compor a sua narrativa, entrelaçando o verossímil e o inverossímil em um mesmo relato, característica do realismo mágico. Apesar disto, o Relato de um náufrago é considerado uma das obras mais realistas do escritor, conhecido pelas narrativas fantásticas. Notícia de um sequestro, Crônica de uma morte anunciada e o premiado Cem Anos de Solidão estão entre os livros aclamados do colombiano.

Depois dos acontecimentos, o náufrago nunca mais foi citado. Gabo ficou por mais de uma década sem ler o relato e, depois de lê-lo, 
concluiu que deveria ser publicado novamente. As publicações foram reunidas e o livro Relato de um náufrago foi lançado em 1970, vinculando o nome do autor à obra pela primeira vez. García Márquez concedeu os direitos de autoria ao náufrago, o que lhe rendeu o sustento durante anos. Ao ganhar o prêmio Nobel de Literatura, em 1982, García Márquez fica famoso e suas obras atingem boas marcas de venda. Alejandro Velasco, querendo tirar proveito, entrou com um processo exigindo os direitos sobre as traduções do Relato. Foram à justiça e, além de perder os direitos sobre as traduções, Velasco também perdeu os que já lhe haviam sido atribuídos.

A história destas publicações, por sua vez, tem muito a ensinar aos novos jornalistas. Muito apegados às novas tecnologias, que podem transcrever a fala de um entrevistado em um documento ao mesmo tempo em que acontece a entrevista, por vezes não se preocupam com a forma do texto. As palavras podem enganar. Reproduzir fielmente o relato de uma fonte sem se atentar às suas expressões é um erro comum. Renegar o papel das emoções - de entrevistado e entrevistador - pode comprometer a verdade e também a beleza de um relato jornalístico.

\section{Referências}

\section{bibliográficas}

Andrews, O. (1957). Caracteres generales de las Sociedades Latinoamericanas. Revista Mexicana de Sociología. 11 (2), mayo - agosto, pp. 423-435.

Herscovitz, H. G. O jornalismo mágico de Gabriel García Márquez (2004). Periódicos. UFSC. 1 (2). Julho-dezembro, pp. 175-195.

Kotscho, R. (1986). A práctica da reportagem. São Paulo: Editora Ática.

Guirado, Maria C. \& Nascimento, A. (2014). Relações Entre a Ficção e Jornalismo em Crônica de uma Morte Anunciada de Gabriel García Márquez. Revista Luciérnaga-Comunicación.
Año 6, N11.Disponível em:

http://www.politecnicojic.edu.co/images/ downloads/publicaciones/revista-luciernaga/ luciernaga-11/pdf/4_muerte_anunciada_ portugues.pdf

García, Márquez, G. (1994). Cem anos de solidão. Rio de Janeiro: Record.

Janeiro, Record, 1993.

Cheiro de goiaba. Rio de

Crônica de uma morte

anunciada. Rio de Janeiro. Record, 2004.

Notícia de um sequestro. Rio

de Janeiro- São Paulo. Record, 1996.

Relato de um náufrago. Rio de Janeiro, Record, 1999.

Viver para conta-la. Lisboa: Publicações Dom Quixote, 2003.

Martin, G. (2010). Gabriel García Márquez: uma vida. Rio de Janeiro: Ediouro.

Peirce, C.S. Collected Papers. C. Hastshorne, P. Weiss \& A. Burks (Ed.), Cambridge: Harvard Univ., 1936-1958.

Escritos coligidos. Trad. Armando Mora D’Oliveira e Sérgio Pomerangblum. São Paulo: Abril Cultural, 1974.

Semiótica. Trad. José Teixeira Coelho. São Paulo: Perspectiva, 1977.

Semiótica e Filosofia. Trad. Octanny Silveira Mota e Leônidas Hegenberg. $3^{\mathrm{a}}$ ed. São Paulo. Cultrix, 1984.

Rodrígues. (1988). S.C. O Fantástico. São Paulo: Ática.

Vogel, D. (2009). Borges e a entrevista. Florianópolis: Insular.

\section{Para citar este artículo:}

Guirado, M. y Souza, C. (2017).

JORNALISMO. Técnicas de reportagem e realismo mágico em Relato de um náufrago, de Gabriel García Márquez.

Revista Luciérnaga / Comunicación. Año 9, N18. Págs. $20-30$

OJS. http://revistas.elpoli.edu.co/index.php/luc/issue/archive

Link. http://www.politecnicojic.edu.co/index.php/revista-luciernaga 